\title{
Modelling thermal fluxes at the soil surface
}

1 José Javier Muñoz-Criollo BSC, MSc, PhD Research Associate, Cardiff School of Engineering, Cardiff University, Cardiff, UK

2 Peter John Cleall BEng, PhD Senior Lecturer, Cardiff School of Engineering, Cardiff University, Cardiff, UK (corresponding author: cleall@cardiff.ac.uk)
3 Stephen William Rees BSc, PhD

Lecturer, Cardiff School of Engineering, Cardiff University, Cardiff, Wales, UK
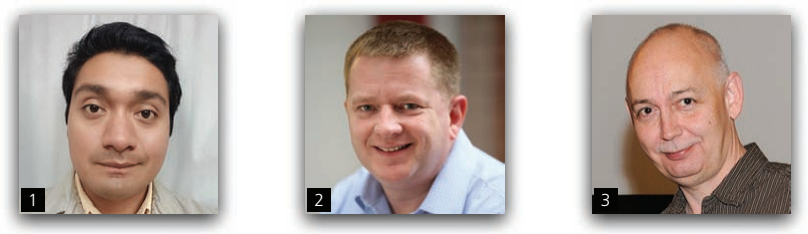

This paper investigates the impact that various representations of thermal fluxes at the soil surface have on the estimation of seasonal variations in temperature and stored thermal energy in the soil close to the surface. Three theoretical formulations representing turbulent, non-turbulent and vegetation-covered soil surface conditions are considered. The influence of shading from nearby objects (e.g. vegetation) has also been investigated. Numerical predictions of soil temperature and stored thermal energy are compared with experimental results from a large-scale field test (performed by others). The results of both one-dimensional and two-dimensional simulations are shown to be capable of representing specific aspects of field behaviour. Various sources of meteorological data have been used to define surface boundary conditions. In particular, simulations were performed using (a) data measured on-site, (b) data obtained from the British Atmospheric Data Centre and (c) data generated using analytical expressions from the literature. It was found that correct representation of the heat transfer processes occurring at the soil surface is of critical importance. In particular, it was found that the use of publicly available sources of data, or mathematical/ analytical expressions for meteorological data, may be adequate when on-site measurements are not available.

\begin{tabular}{|c|c|c|c|}
\hline Notation & & $q_{\mathrm{a}}$ & air vapour pressure: $\mathrm{kPa}$ \\
\hline$A$ & summer daily average solar radiation: $\mathrm{W} / \mathrm{m}^{2}$ & $q_{\mathrm{G}}$ & surface vapour pressure: $\mathrm{kPa}$ \\
\hline$B$ & winter daily average solar radiation: $\mathrm{W} / \mathrm{m}^{2}$ & $q_{\text {sat }}$ & saturated vapour pressure: $\mathrm{kPa}$ \\
\hline$C$ & midsummer daily average air temperature: ${ }^{\circ} \mathrm{C}$ & $R$ & solar radiation: $\mathrm{W} / \mathrm{m}^{2}$ \\
\hline \multirow[t]{2}{*}{$C_{\mathrm{e}}$} & fully dense canopy cover evaporation & $R_{1}=0.5(A-B)$ & solar radiation coefficient: $\mathrm{W} / \mathrm{m}^{2}$ \\
\hline & coefficient & $R_{2}=0 \cdot 5(A+B)$ & solar radiation coefficient: $\mathrm{W} / \mathrm{m}^{2}$ \\
\hline$C_{\mathrm{fc}}$ & forced convection weighing coefficient & $R_{\mathrm{d}}$ & effective solar radiation: $\mathrm{W} / \mathrm{m}^{2}$ \\
\hline \multirow[t]{2}{*}{$C_{\mathrm{nc}}$} & natural convection weighing coefficient: & $r_{\mathrm{a}, \mathrm{c}}$ & canopy cover aerodynamic resistance: $\mathrm{s} / \mathrm{m}$ \\
\hline & $\mathrm{m} /\left(\mathrm{s}^{\circ} \mathrm{C}^{1 / 3}\right)$ & $r_{\mathrm{s}}$ & stomata resistance: $\mathrm{s} / \mathrm{m}$ \\
\hline$C_{\mathrm{sh}}$ & sheltering coefficient & $T$ & soil temperature: ${ }^{\circ} \mathrm{C}$ \\
\hline$c_{\mathrm{p}, \mathrm{a}}$ & specific heat capacity of air: $\mathrm{J} /(\mathrm{kg} \mathrm{K})$ & $T_{1}=0.5(C-D)$ & air temperature coefficient: ${ }^{\circ} \mathrm{C}$ \\
\hline$D$ & midwinter daily average air temperature: ${ }^{\circ} \mathrm{C}$ & $T_{2}=0 \cdot 5(C+D)$ & air temperature coefficient: ${ }^{\circ} \mathrm{C}$ \\
\hline$D_{\mathrm{s}}$ & diurnal shading factor & $T_{3}=0.5(E-F)$ & air temperature coefficient: ${ }^{\circ} \mathrm{C}$ \\
\hline \multirow[t]{2}{*}{$E$} & midsummer average amplitude air & $T_{4}=0.5(E+F)$ & air temperature coefficient: ${ }^{\circ} \mathrm{C}$ \\
\hline & temperature: ${ }^{\circ} \mathrm{C}$ & $T_{\mathrm{a}, \mathrm{k}}$ & air absolute temperature: $\mathrm{K}$ \\
\hline \multirow[t]{2}{*}{$F$} & midwinter average amplitude air temperature: & $T_{\mathrm{c}, \mathrm{k}}$ & canopy cover absolute temperature: $\mathrm{K}$ \\
\hline & ${ }^{\circ} \mathrm{C}$ & $T_{\mathrm{k}}$ & surface absolute temperature: $\mathrm{K}$ \\
\hline$h_{\mathrm{C}}$ & convective heat transfer coefficient: $\mathrm{W} /\left(\mathrm{m}^{2} \mathrm{~K}\right)$ & $t$ & time: $\mathrm{s}$ \\
\hline \multirow[t]{2}{*}{$h_{\mathrm{E}}$} & evaporative heat transfer coefficient: & $U$ & wind velocity: $\mathrm{m} / \mathrm{s}$ \\
\hline & $\mathrm{W} /\left(\mathrm{m}^{2} \mathrm{~K}\right)$ & $\alpha$ & soil thermal diffusivity: $\mathrm{m}^{2} / \mathrm{s}$ \\
\hline$k$ & soil thermal conductivity: W/(m K) & $\alpha_{\mathrm{c}}$ & canopy cover albedo \\
\hline$L_{\mathrm{V}}$ & latent heat of vaporisation of water: $\mathrm{J} / \mathrm{kg}$ & $\alpha_{\mathrm{s}}$ & surface albedo \\
\hline
\end{tabular}




$\begin{array}{ll}\gamma & \text { daily period: } \mathrm{s}^{-1} \\ \varepsilon_{\mathrm{c}} & \text { canopy cover infrared emissivity } \\ \mathcal{E}_{\mathrm{G}} & \text { surface infrared emissivity } \\ \varepsilon_{\mathrm{s}} & \text { sky infrared emissivity } \\ \theta_{\mathrm{v}, \mathrm{a}} & \text { air virtual temperature: }{ }^{\circ} \mathrm{C}^{1 / 3} \\ \theta_{\mathrm{v}, \mathrm{s}} & \text { surface virtual temperature: }{ }^{\circ} \mathrm{C}^{1 / 3} \\ v & \text { canopy cover density } \\ \rho_{\mathrm{a}} & \text { air density: } \mathrm{kg} / \mathrm{m}^{3} \\ \sigma & \text { Stefan-Boltzmann constant: } \mathrm{W} /\left(\mathrm{m}^{2} \mathrm{~K}^{4}\right) \\ \phi & \text { annual period: } \mathrm{s}^{-1}\end{array}$

\section{Introduction}

The estimation of both thermal fluxes at the soil surface and shallow temperature profiles is important for the design of several engineering applications that either are in direct contact with or otherwise use the soil as a reservoir/source of thermal energy. Typical examples include ground source heating (Florides and Kalogirou, 2007), reduction of thermal losses and passive heating and cooling of buildings (Rees et al., 2000; Zoras, 2009) and interseasonal thermal energy storage (Bobes-Jesus et al., 2013; Muñoz-Criollo et al., 2016; Pinel et al., 2011). The study and assessment of infrastructure and systems that store or extract thermal energy from the ground requires an ability to correctly represent the temperature profile of the soil and the amount of energy stored in it as well as to accurately describe the heat fluxes occurring on its surface.

In general, surface fluxes are considered to consist of four main components, namely: solar radiation, infrared radiation, convection and evaporation. A number of approaches have been developed to represent these fluxes either individually or in total for various weather and ground surface conditions. Three different formulations of heat transfer coefficients are considered here and implemented in a transient thermal finite-element model. The first formulation, proposed by Jansson et al. (2006), represents the heat flux from a road surface and was developed assuming turbulent atmospheric conditions. Two further formulations discussed by Herb et al. (2008) are then considered. The first of these was developed by Edinger and Brady (1974) and accounts for natural convection, implying that it can be applied for nonturbulent heat transfer processes. The second formulation takes into account canopy cover and is based on the findings of Best (1998) and the work of Deardorff (1978). This formulation describes the heat transfer interactions between the system formed by the soil surface, canopy cover (e.g. vegetation) and the atmosphere. Furthermore, diurnal shading due to surrounding features is also taken into account.

This paper focuses on the representation of these surface energy fluxes by way of the aforementioned theoretical approaches utilising meteorological data measured on-site as well as data obtained from public meteorological stations and meteorological data generated using analytical expressions from the literature. These approaches are then assessed, in terms of their ability to represent real-world conditions, by comparing them with a comprehensive experimental dataset obtained from a large-scale field test performed by Carder et al. (2007) as part of a 2-year demonstration project of an interseasonal heat storage facility commissioned by the UK Highways Agency. Results of a series of transient analyses of the field experiment are presented and compared with the experimental observations in terms of both soil temperature and stored energy. The research explores the use of a one-dimensional (1D) simulation to predict behaviour remote from the influence of the storage facility. However, a two-dimensional (2D) simulation is employed to represent the overall heat transfer characteristics in the vicinity of the experimental facility.

\section{Theoretical and numerical model}

The objective of this paper is to study the variation in thermal energy stored in shallow regions of the soil profile that arises from different assumptions regarding the representation of thermal heat fluxes at the soil surface. In order to simplify the analysis, only heat transfer by conduction is considered in the soil mass, while other physical processes such as convection and mechanical deformation are neglected. The impact of thermohydraulic coupling within the soil domain has been investigated and found to have a negligible impact on the prediction of the thermal behaviour of the systems under consideration here (MuñozCriollo, 2014). The model presented is based on the transient heat transfer equation

1. $\nabla^{2} T=\frac{1}{\alpha} \frac{\mathrm{d} T}{\mathrm{~d} t}$

Equation 1 is solved using a mixed boundary condition at the soil surface that takes into account solar and infrared radiation, convection and evaporation, yielding

$$
\begin{gathered}
-k \frac{\mathrm{d} T}{\mathrm{~d} x}=\left(1-\alpha_{\mathrm{s}}\right) R+\sigma \varepsilon_{\mathrm{G}}\left(\varepsilon_{\mathrm{s}} T_{\mathrm{a}, \mathrm{k}}^{4}-T_{\mathrm{k}}^{4}\right) \\
\text { 2. } \quad+h_{\mathrm{E}}\left(q_{\mathrm{a}}-q_{\mathrm{G}}\right)+h_{\mathrm{C}}\left(T_{\mathrm{a}}-T\right)
\end{gathered}
$$

The values of the parameters in Equation 2 are, in general, dependent on the physical characteristics of the surface and the atmospheric conditions. It is recognised that while heat fluxes related to evaporation and natural convection at the soil surface are considered, the net mass transfer implied by this is ignored in the approach adopted here. The albedo of the surface, $\alpha_{\mathrm{s}}$, will be affected by a number of factors, including, for example, its colour (Pascual-Muñoz et al., 2014).

Two approaches are investigated in this study to compare the impact that alternative theoretical formulations of the convective and evaporative heat transfer coefficients may have on the predicted heat transfer between the soil and the atmosphere and the amount of energy stored in the ground. Suitable values for the coefficients in Equation 2 and those found in the following subsections are summarised in Table 1. 


\begin{tabular}{|c|c|c|c|c|c|}
\hline Variable & Value & Variable & Value & Variable & Value \\
\hline $\boldsymbol{g}: \mathrm{m} / \mathrm{s}^{2}$ & $9 \cdot 8$ & $\varepsilon_{\mathrm{G}}($ road $)$ & 0.94 & $C_{e}$ & 1 \\
\hline$L_{v}: J / k g$ & $2 \cdot 45 \times 10^{6}$ & $\alpha_{\mathrm{s}}($ road $)$ & $0 \cdot 12$ & $C_{\mathrm{fc}}$ & 0.0015 \\
\hline$\sigma: \mathrm{W} /\left(\mathrm{m}^{2} \mathrm{~K}^{4}\right)$ & $5.67 \times 10^{-8}$ & $\varepsilon_{\mathrm{G}}($ soil $)$ & 0.95 & $C_{n c}: m /\left(s K^{1 / / 3}\right)$ & 0.0015 \\
\hline$\rho_{\mathrm{a}}: \mathrm{kg} / \mathrm{m}^{3}$ & $1 \cdot 2041$ & $\alpha_{\mathrm{s}}($ soil $)$ & $0 \cdot 15$ & $C_{\text {sh }}$ & 1 \\
\hline$c_{p, a}: J /(k g K)$ & 1012 & $\varepsilon_{\mathrm{G}}($ canopy cover) & 0.95 & $\phi$ & $2 \pi / 31557600 \mathrm{~s}$ \\
\hline$k_{\mathrm{vk}}$ & $0 \cdot 41$ & $\alpha_{\mathrm{s}}($ canopy cover) & $0 \cdot 15$ & $\gamma$ & $2 \pi / 86400 \mathrm{~s}$ \\
\hline$v$ & 0.85 & & & & \\
\hline
\end{tabular}

Table 1. Summary of variables and constants used to calculate parameters presented in the section titled 'Theoretical and numerical model'

The first theoretical approach considered was proposed by Edinger and Brady (1974) to analyse the heat transfer between water surfaces and the atmosphere. However, it can be readily applied to pavement and soil surfaces by adjusting the parameters as suggested by Herb et al. (2008). This approach takes into account the effect of natural and forced convection in the heat transfer coefficients for convection and evaporation. They are defined as

3. $h_{\mathrm{E}}=\rho_{\mathrm{a}} L_{\mathrm{v}}\left[C_{\mathrm{fc}} C_{\mathrm{sh}} u+C_{\mathrm{nc}}\left(\theta_{\mathrm{v}, \mathrm{s}}-\theta_{\mathrm{v}, \mathrm{a}}\right)^{1 / 3}\right]$

4. $h_{\mathrm{C}}=\rho_{\mathrm{a}} c_{\mathrm{p}, \mathrm{a}}\left[C_{\mathrm{fc}} C_{\mathrm{sh}} u+C_{\mathrm{nc}}\left(\theta_{\mathrm{v}, \mathrm{s}}-\theta_{\mathrm{v}, \mathrm{a}}\right)^{1 / 3}\right]$

The virtual temperature $\theta_{\mathrm{v}}$ is often employed in meteorology and is introduced when working with moist air since it allows the use of the ideal gas law for dry air (North and Erukhimova, 2009). In the case of a paved surface, no evaporation is considered. This implicitly assumes that the surface is impermeable and that any water from rainfall is rapidly removed by way of surface drainage.

The second theoretical approach used here to represent surface conditions was developed by Best (1998) and Deardorff (1978). This method takes into account the presence of vegetation cover at the soil surface, thereby adding an additional soil-atmosphere process. The boundary condition for this case is similar to Equation 2 except that the heat flux components are weighted by the presence of the canopy cover density $v$. The resulting equation is

$$
\begin{aligned}
-k \frac{\mathrm{d} T}{\mathrm{~d} x} & =\left(1-\alpha_{\mathrm{s}}\right)(1-v) R \\
& +\left\{\sigma \varepsilon_{\mathrm{G}}\left[(1-v) \varepsilon_{\mathrm{s}} T_{\mathrm{a}, \mathrm{k}}^{4}-T_{\mathrm{k}}^{4}\right]+v \varepsilon_{\mathrm{c}} \sigma T_{\mathrm{c}, \mathrm{k}}^{4}\right\} \\
& +h_{\mathrm{E}}\left(1-C_{\mathrm{e}} v\right)\left(q_{\mathrm{a}}-q_{\mathrm{G}}\right) \\
& +h_{\mathrm{C}}\left(1-C_{\mathrm{e}} v\right)\left(T_{\mathrm{a}}-T\right)
\end{aligned}
$$

The constant $C_{\mathrm{e}}$ dictates the level of soil evaporation and convection for fully dense canopies. The heat balance equation for the canopy cover (which is assumed to have negligible heat capacity) is then given by

$$
\left(1-\alpha_{\mathrm{c}}\right) v R+v \sigma \varepsilon_{\mathrm{G}} \varepsilon_{\mathrm{s}} T_{\mathrm{a}, \mathrm{k}}^{4}-2 v \sigma \varepsilon_{\mathrm{c}} T_{\mathrm{c}, \mathrm{k}}^{4}+v \sigma \varepsilon_{\mathrm{G}} T_{\mathrm{k}}^{4}
$$

6. $+\frac{\rho_{\mathrm{a}} L_{\mathrm{v}} v}{r_{\mathrm{a}, \mathrm{c}}+r_{\mathrm{s}}}\left[q_{\mathrm{a}}-q_{\mathrm{sat}}\left(T_{\mathrm{c}}\right)\right]+\frac{\rho_{\mathrm{a}} c_{\mathrm{p}, \mathrm{a}} v}{r_{\mathrm{a}, \mathrm{c}}}\left(T_{\mathrm{a}}-T_{\mathrm{c}}\right)=0$

Expressions for canopy cover aerodynamic resistance $r_{\mathrm{a}, \mathrm{c}}$ and stomata resistance $r_{\mathrm{s}}$ can be found in Best (1998) and Deardorff (1978).

In addition to the mentioned formulations for heat transfer coefficients, the effect of shading due to nearby objects (e.g. trees) on the surface temperature of a paved surface is also explored here by modifying the solar radiation term to include a factor, $D_{\mathrm{s}}$, to account for the impact of shading

7. $R_{\mathrm{d}}=R D_{\mathrm{s}}$

Depending on the conditions, the shading factor will have a value between 1 for a completely transparent object and 0 for a fully opaque object.

As mentioned previously, this paper aims to explore the use of alternative sources of meteorological data to define the surface boundary conditions. To this end, analytical expressions for air temperature and solar radiation can be constructed using widely available averaged meteorological data. The detailed formulation and verification of this approach was provided by Cleall et al. (2015). In brief, the solar radiation can be defined as

$$
R(t)=\frac{\pi}{2}\left[\cos ^{2}(\gamma t)-\cos (\gamma t)+\frac{4-\pi}{2 \pi}\right]\left[R_{1} \cos (\phi t)+R_{2}\right]
$$

8. 
Environmental Geotechnics

Volume 6 Issue EG6
Modelling thermal fluxes at the soil

surface

Muñoz-Criollo, Cleall and Rees whereas the expression for air temperature is defined as

$$
\begin{aligned}
T_{\mathrm{a}}(t)= & T_{1}[\cos (\phi t)+0 \cdot 5 \sin (\phi t)]+T_{2} \\
& -\left\{T_{3}[\cos (\phi t)+0 \cdot 5 \sin (\phi t)]+T_{4}\right\} \cos (\gamma t)
\end{aligned}
$$

In this study, when such analytical expressions are employed, relative humidity and wind speed are considered constant and equal to yearly averaged values based on available experimental data (Cleall et al., 2015).

A 2D numerical model based on the finite-element method has been developed to solve the transient heat diffusion equation given by Equation 1 by using Equations 2 or 5 and 6 (as appropriate) as boundary conditions for the soil surface. Time discretisation is performed using a Crank-Nicholson scheme. This model has been verified against the analytical solutions presented in Cleall et al. (2015), and full details are available in MuñozCriollo (2014). The model can easily be constrained to represent 1D conditions where desirable.

\section{Case study}

The experimental measurements used in this study were provided by the Transport Research Laboratory (TRL) (Carder et al., 2007). The TRL, under the commission of the UK Highways Agency (HA), measured soil temperatures as part of a 2-year demonstration project between July 2005 and May 2007 at Toddington, UK.

Boreholes up to $12.875 \mathrm{~m}$ deep were drilled to accommodate temperature sensor arrays. Measurements from two of these boreholes, located under different surface conditions as shown in Figure 1, are used for comparison with numerical results. Borehole 1 (Bh1) was situated at the southern end of the experimental site and was used to record the soil temperature variations under natural surface conditions. It can be seen that $\mathrm{Bh} 1$ was partially covered by grass. No details regarding regular surface maintenance above Bh1 (e.g. grass cutting) were provided by Carder et al. (2007). However, site visits by the authors indicate that it is

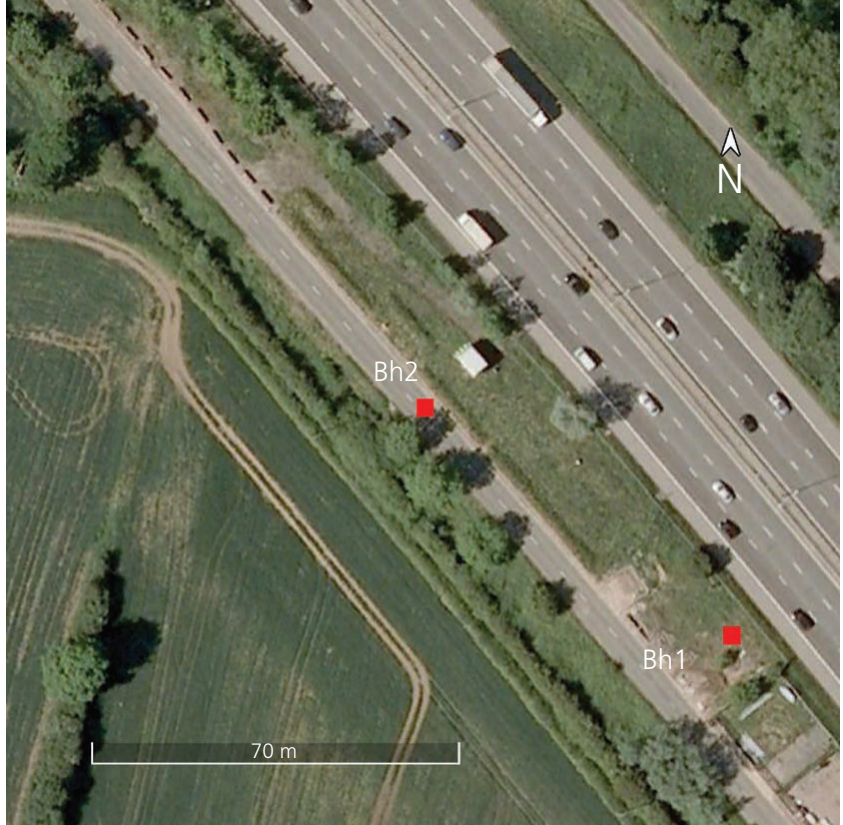

Figure 1. Position of boreholes Bh1 and Bh2 after Carder et al. (2007). Aerial photograph taken from Google Maps (2012). Images (C2012 Digital Globe, GeoEye, Getmapping plc, Infoterra Ltd \& Bluesky, The Geolnformation Group, Map data @2012 Google

reasonable to assume that the surface was subject to a natural cycle of plant (mainly grass) growth. Borehole $2(\mathrm{Bh} 2)$ provided a record of the temperature variations directly under the paved road surface. Figure 1 suggests that $\mathrm{Bh} 2$ was subject to partial shading by nearby trees located at the edge of the road. This assumption is further supported by the results shown in Figure 2, which compares measured temperatures at $0.01 \mathrm{~m}$ at $\mathrm{Bh} 1$ and $\mathrm{Bh} 2$ for a typical 3-d period (similar behaviour can be observed on many other days). In addition to the obvious difference in temperature due to the surface properties, a temperature drop in the data for the pavement surface, which is not present in the data for the soil surface, can be seen between approximately 12.00 and $15.00 \mathrm{~h}$.

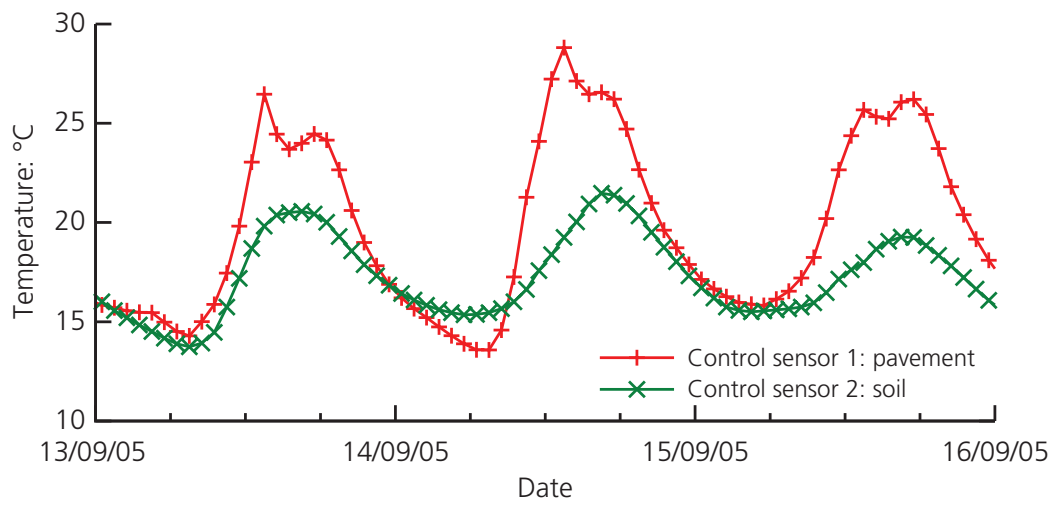

Figure 2. Temperatures at $0.025 \mathrm{~m}$ depth for boreholes Bh1 (soil) and Bh2 (pavement). Data from Carder et al. (2007) 


\begin{tabular}{lcccc}
\hline \multirow{2}{*}{ Symbol } & Parameter & \multicolumn{3}{c}{ Material } \\
\cline { 3 - 5 } & & Soil & Pavement & Concrete \\
\hline$k$ & Thermal conductivity: & $1 \cdot 2$ & 0.85 & $1 \cdot 4$ \\
& $W /(m$ K) & & & \\
$\rho$ & Density: $\mathrm{kg} / \mathrm{m}^{3}$ & 1960 & 2400 & 2100 \\
$c_{p}$ & Specific capacity: J/(kg K) & 840 & 850 & 840
\end{tabular}

Table 2. Material parameters used in 1D and 2D domains shown in Figure 3 (Carder et al., 2007)

Material properties for the soil and constitutive layers of the road were provided by Carder et al. (2007) and are summarised in Table 2. Soil properties have also been measured from samples recovered from a site investigation of the experimental area (Muñoz-Criollo, 2014) with the moisture content for the clay near the surface (up to $0.65 \mathrm{~m}$ depth) having an average value of $0 \cdot 24$. The properties reported by Carder et al. (2007) and the measured values are also in reasonable agreement with those provided by Garratt (1994), who reported properties as a function of the degree of saturation for clay soils. Meteorological measurements carried on-site by TRL include solar radiation, air temperature, wind speed, relative humidity and precipitation every $15 \mathrm{~min}$ from July 2005 to May 2007. This dataset was used in this study in comparison with alternative weather data sources. When analytical expressions are adopted to describe variations in solar radiation and air temperature, the values of the coefficients used in Equations 8 and 9 (detailed in Table 3) are determined based on this dataset.

\section{Numerical investigation}

A series of numerical simulations was performed to explore certain characteristics of the experiment. To this end, both 1D and 2D simulations were undertaken. 1D simulations were used to explore conditions remote from the paved regions and $2 \mathrm{D}$ simulations

\begin{tabular}{lccc}
\hline Variable & Value & Variable & Value \\
\hline$A$ & $204.2 \mathrm{~W} / \mathrm{m}^{2}$ & $D$ & $3 \cdot 6^{\circ} \mathrm{C}$ \\
$B$ & $21.3 \mathrm{~W} / \mathrm{m}^{2}$ & $E$ & $2 \cdot 7^{\circ} \mathrm{C}$ \\
$C$ & $15 \cdot 4^{\circ} \mathrm{C}$ & $F$ & $4 \cdot 2^{\circ} \mathrm{C}$
\end{tabular}

Table 3. Values used to calculate coefficients present in Equations 8 and 9 (UK Meteorological Office, 2012)

were used to explore the overall behaviour across the domain. Specifically, the numerical investigation considers

- two alternative theoretical representations of soil surface boundary conditions using the heat transfer coefficients presented in the section titled 'Theoretical and numerical model'

- additional variations in the level of solar radiation reaching the soil surface caused by the presence of nearby objects (not commonly included in traditional soil surface theoretical representations)

n the use of alternative sources of meteorological data to describe soil surface boundary conditions.

\section{D simulation of far-field soil conditions (Bh1)}

A preliminary set of $1 \mathrm{D}$ numerical simulations is presented in this section. The domain under consideration, shown in Figure 3(c), was discretised, after spatial convergence tests, with a uniform mesh consisting of 1024 elements and is assumed to be composed of a single material (clay). Physical and thermal properties are listed in Table 2. The lower boundary condition is set as adiabatic. Two theoretical formulations are considered to describe boundary conditions at the soil surface. Equation 2 is used to describe bare soil conditions, and Equations 5 and 6 describe the presence of a vegetation cover. By using these formulations, it was found that the system reached a quasi-steadystate condition (that is, the same temperature profile at the same



Figure 3. Domains considered in this study: (a) full 2D domain;

(b) zoom-in of road section; (c) 1D domain 
point in time during a yearly cycle) after eight yearly cycles. This profile is then used as a representative initial condition. This approach allows a realistic approximation of the non-homogenous initial conditions (that is, the natural variation in soil temperature with depth due to daily and annual climate variations). A time step size of $1 \mathrm{~h}$ was maintained, after temporal convergence tests, and the meteorological data measured on-site by Carder et al. (2007) were employed. The subsequent numerical simulation was in effect a ninth yearly cycle. These results were compared with the experimental measurements recorded at borehole Bh1 (Figure 1). Statistical analysis yielded the root-mean-square errors (RMSEs) from these comparisons, which are summarised in Table 4.

Figure 4 shows a comparison of experimental and numerical results achieved using both the canopy (vegetation) cover and the bare soil surface theoretical formulations. The results show soil temperatures every $6 \mathrm{~h}$ at $0.025 \mathrm{~m}$ depth for the period between September 2005 and August 2006. Figure 5 provides the time variation of hourly soil temperature values at the same depth for the period 9-21 October 2005. Returning to Figure 4, it can be seen that the temperatures predicted at $0.025 \mathrm{~m}$ depth by the canopy cover formulation tend to be closer to the experimental observations, while the predictions achieved using the bare soil formulation tend to be more scattered, with a bias towards higher temperatures. An experimental maximum temperature of $28^{\circ} \mathrm{C}$ was reached in July, whereas predicted maximum temperatures of 30 and $38^{\circ} \mathrm{C}$ were obtained from the canopy cover and bare soil formulations, respectively. Conversely, the minimum predicted temperatures obtained during winter months were -4 and $-6^{\circ} \mathrm{C}$ using the canopy cover and bare soil conditions, respectively. However, it can be seen that experimental temperatures in this period did not drop below $0^{\circ} \mathrm{C}$. This anomaly could be related to the impact of snow fall events on particularly cold days that would effectively insulate the soil from the extreme atmospheric conditions. In addition, seasonal changes in the canopy cover (wilt, decay and fall) could also contribute to insulate the soil surface further (effectively increasing the value of $v$ in Equations 5 and 6) from atmospheric conditions. It is recognised that both of

\begin{tabular}{lcc}
\hline & \multicolumn{2}{c}{ RMSE } \\
\cline { 2 - 3 } & Canopy cover & Bare soil \\
\hline Depth of $0.025 \mathrm{~m}$ & $2.01^{\circ} \mathrm{C}$ & $3.41^{\circ} \mathrm{C}$ \\
Depth of $0.875 \mathrm{~m}$ & $1.76^{\circ} \mathrm{C}$ & $0.90^{\circ} \mathrm{C}$ \\
Energy & $3.76 \mathrm{MJ} / \mathrm{m}^{2}$ & $8.53 \mathrm{MJ} / \mathrm{m}^{2}$
\end{tabular}

Table 4. RMSE values between experimental and numerical data corresponding to soil temperatures (Bh1) at two different depths and seasonal thermal energy stored in a $12.875 \mathrm{~m}$ deep column of soil

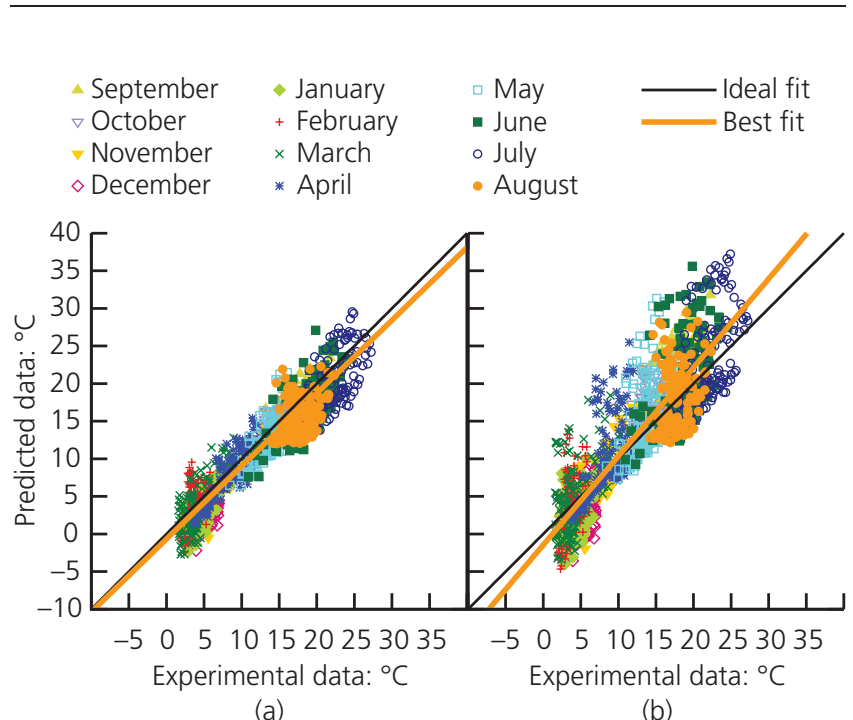

Figure 4. Scatter plots of experimental and predicted temperatures at $0.025 \mathrm{~m}$ depth using boundary conditions for (a) canopy cover and (b) bare soil

these physical processes have not been considered in this study. Nevertheless, the results suggest that the canopy cover acts as a buffer between the atmosphere and soil that otherwise would be

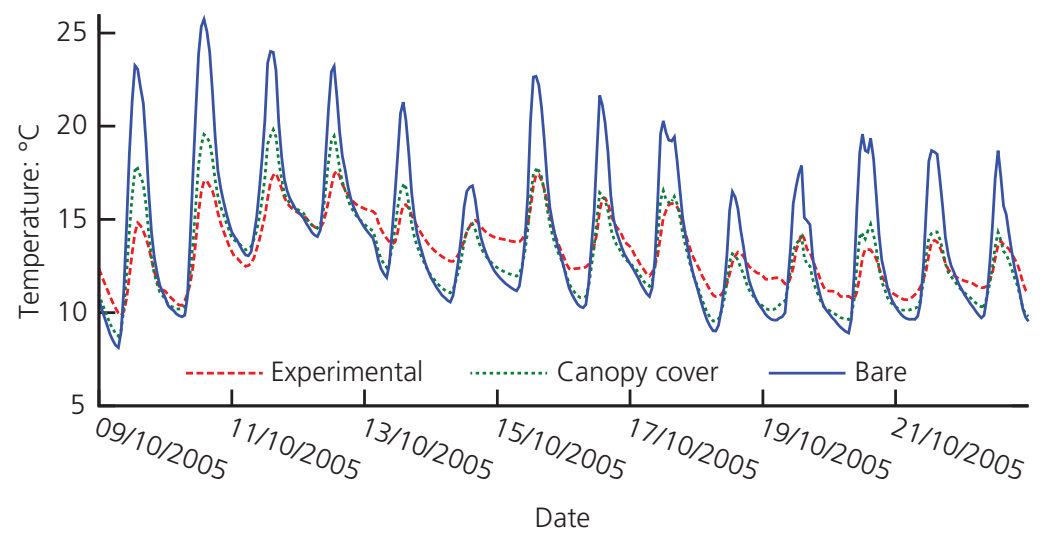

Figure 5. Temperature variation with time at 0.025-m depth using

boundary conditions for canopy cover and bare soil 
Environmental Geotechnics

Volume 6 Issue EG6
Modelling thermal fluxes at the soil

surface

Muñoz-Criollo, Cleall and Rees fully exposed, allowing it to reach higher temperatures in summer and slightly lower temperatures in winter months. This can be more easily appreciated in Figure 5: diurnal temperatures predicted using a canopy cover tend to be in better agreement with the experimental results, while the bare soil results are comparatively higher. However, in both cases, the nocturnal temperatures tend to be underestimated - with slightly lower values under bare soil conditions. It is suggested that this may be the result of the model not following the natural daily variations in relative humidity and soil evaporation. In fact, it is assumed here that the soil moisture content is constant, and this dictates the numerical evaluation of daily evaporative heat fluxes.

Figure 6 shows a comparison of experimental and numerical predictions (using canopy cover and bare soil surface formulations) of hourly soil temperatures at a depth of $0.875 \mathrm{~m}$ for the period between September 2005 and August 2006, while Figure 7 provides a comparison of the daily average soil temperatures at depths of 0.025 and $0.875 \mathrm{~m}$ for the same period. It can be observed that the temperature variation at $0.875 \mathrm{~m}$ is reduced to approximately $50 \%$

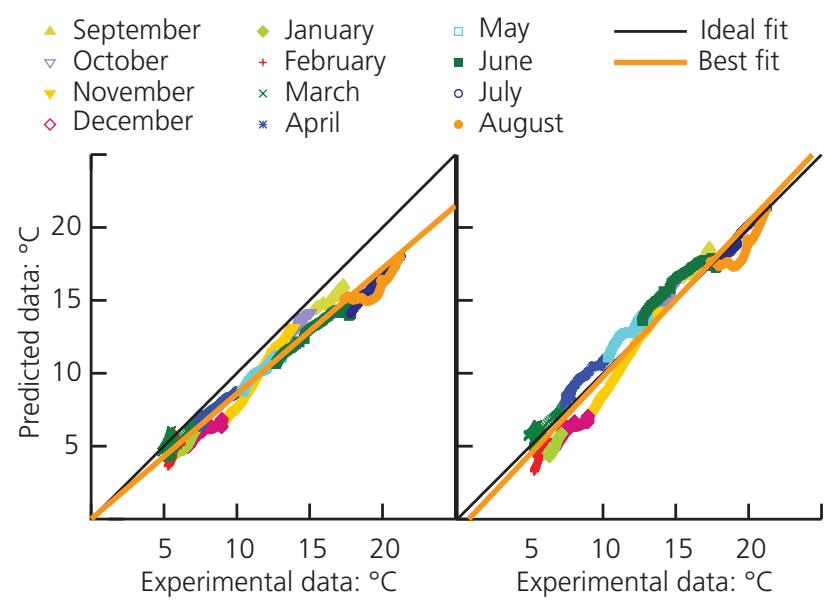

(a)

(b)

Figure 6. Scatter plots of experimental and predicted temperatures at $0.875 \mathrm{~m}$ depth using boundary conditions for (a) canopy cover and (b) bare soil
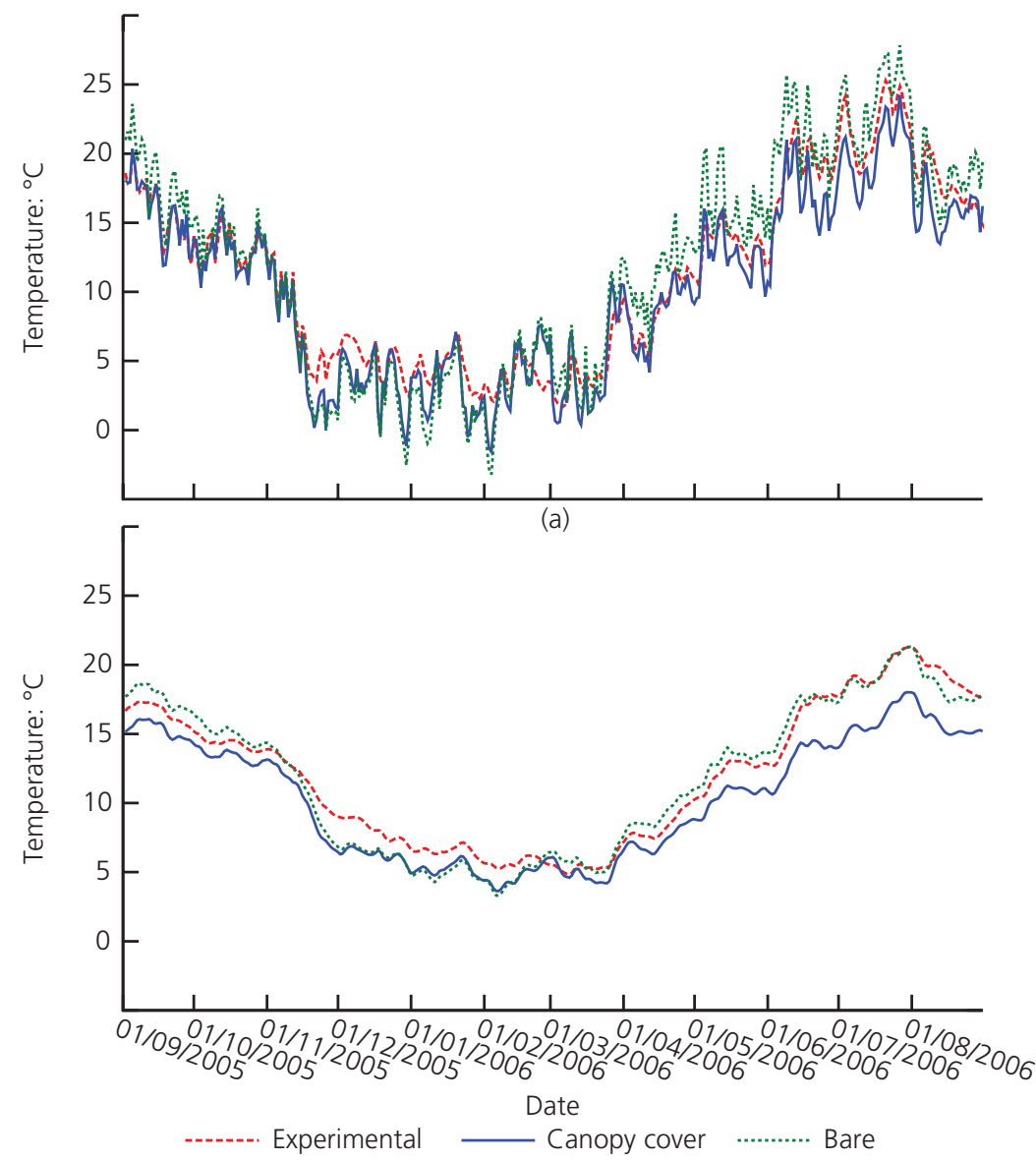

(b)

Figure 7. Seasonal daily average soil temperature variations at

(a) 0.025 and (b) $0.875 \mathrm{~m}$ depths using boundary conditions for canopy cover and bare soil 
Environmental Geotechnics

Volume 6 Issue EG6
Modelling thermal fluxes at the soil

surface

Muñoz-Criollo, Cleall and Rees of that at $0.025 \mathrm{~m}$ (Figure 4) and there is also a phase shift in soil temperatures with depth. For example, maximum temperatures close to the surface (at a depth of $0.025 \mathrm{~m}$ ) under both canopy cover and bare surface conditions are reached at the end of June and the beginning of July, while corresponding maximums at $0.875 \mathrm{~m}$ are obtained at the end of July and the beginning of September. At $0.875 \mathrm{~m}$, the canopy cover results tend to underestimate soil temperatures by up to $4^{\circ} \mathrm{C}$ in the summer months and by approximately $1.5^{\circ} \mathrm{C}$ in the winter months. This behaviour could be related to the comparatively higher amount of solar radiation that is prevented from reaching the soil by the presence of the canopy cover during summer. Furthermore, seasonal changes in this cover under natural conditions are not considered in this study, where a constant value of canopy density is used through the year. Conversely, a bare soil surface assumption seems to produce results that are in better agreement with experimental measurements during late summer months while underestimating, by up to $3^{\circ} \mathrm{C}$, the soil temperatures in winter and overestimating, by approximately $2^{\circ} \mathrm{C}$, the temperatures in the spring and early summer. As discussed earlier, the temperatures at the surface tend to be in better agreement when a canopy cover formulation is employed. Nevertheless, the results underestimate the temperatures at $0.825 \mathrm{~m}$ depth. This might indicate that under the assumptions made in this study, the effect of the canopy cover in the model is to reduce successfully the surface heating due to solar radiation in daytime but at the same time overestimate the surface temperature reduction at night-time (Figure 5).

Figures 8 and 9 provide a comparison of experimentally derived and numerically predicted relative thermal energy stored in the $12 \cdot 875 \mathrm{~m}$ deep soil column. The relative thermal energy contained in the soil was calculated by adopting the approach outlined by Cleall et al. (2015). The soil temperature profiles were obtained from both the experimental and numerical data by using linear

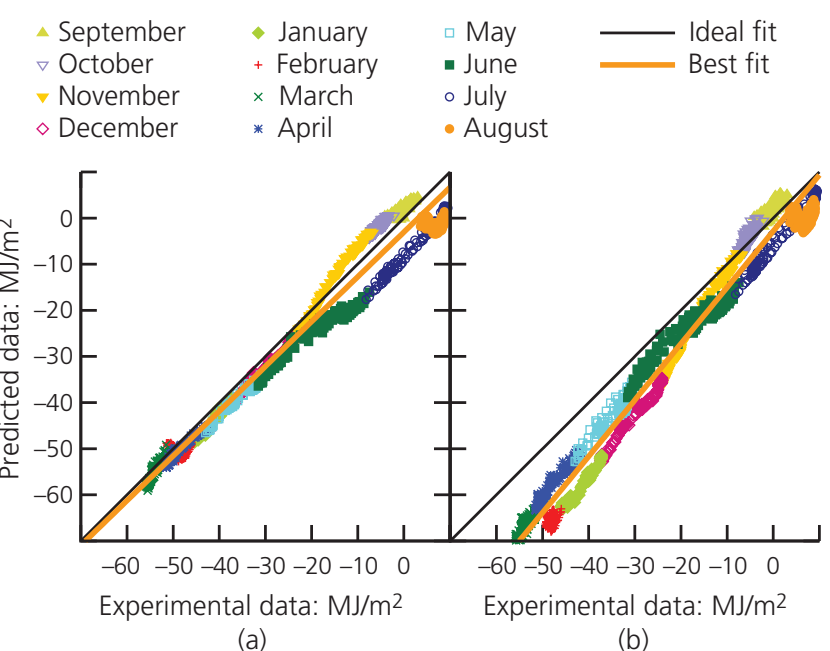

(a)

(b)

Figure 8. Scatter plots of experimental and predicted stored relative thermal energy in a column of soil $12.875 \mathrm{~m}$ depth using boundary conditions for (a) canopy cover and (b) bare soil

interpolation. Data were available at 11 points corresponding to the 11 temperature sensors located at different depths. The exact locations of these sensors and further soil thermal properties are detailed in Carder et al. (2007). The initial reference date for this calculation is set as 1 September 2005 (at $0.00 \mathrm{~h}$ ).

Figure 9 shows that the relative thermal energy stored derived from the experimental data varies seasonally by approximately $55 \mathrm{MJ} / \mathrm{m}^{2}$. The corresponding calculation based on the simulated results yields variations of 60 and $70 \mathrm{MJ} / \mathrm{m}^{2}$ for the canopy cover and bare surface simulations, respectively (these results are similar to those obtained by Cleall et al. (2015) using Equations 8 and 9 to estimate equivalent seasonal variations in thermal energy). It can be

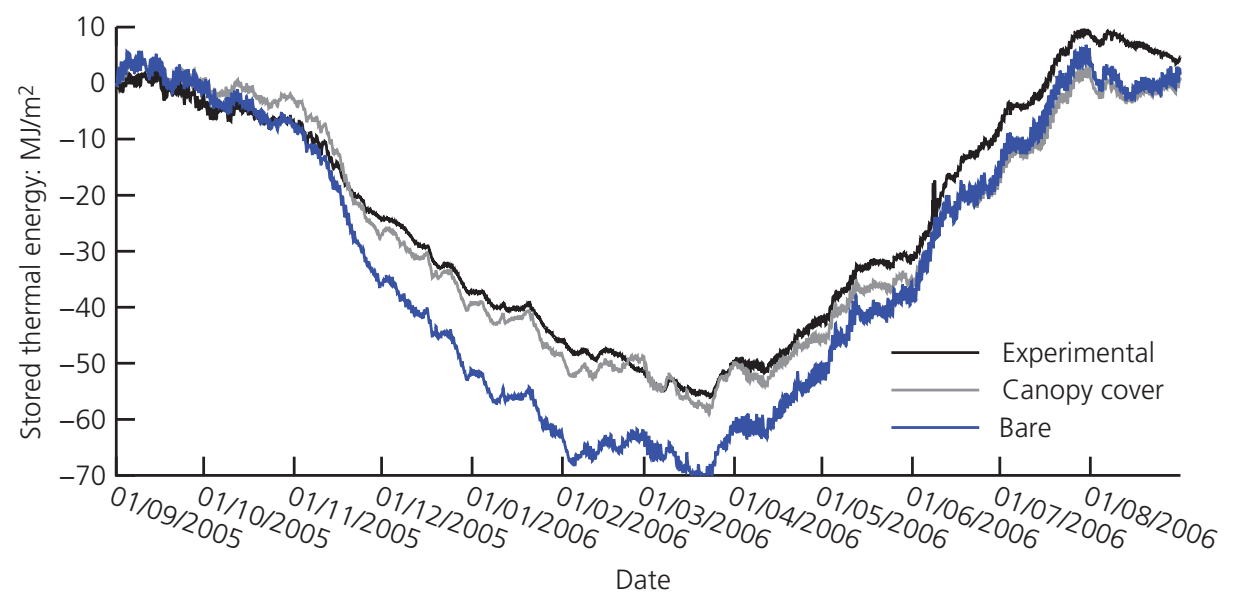

Figure 9. Comparison of experimental measurements and numerical results of seasonal variation in relative thermal energy stored in a column of soil $12.875 \mathrm{~m}$ depth using boundary conditions for canopy cover and bare soil 
observed that, although, in general, the seasonal variation in thermal energy obtained using a canopy cover is in better agreement with experimental results, specific values for summer and autumn months tend to be underpredicted by approximately $3 \mathrm{MJ} / \mathrm{m}^{2}$ and overpredicted by approximately $5 \mathrm{MJ} / \mathrm{m}^{2}$, respectively. Under bare soil conditions, it can be seen that the amount of thermal energy present in the soil during winter and spring months is noticeably underpredicted by approximately $15 \mathrm{MJ} / \mathrm{m}^{2}$.

\section{D simulation of pavement surface conditions ( $\mathrm{Bh} 2$ )}

A series of 2D simulations is presented in this section. The domain and mesh under consideration is shown in Figure 3(a). The mesh was constructed using 2452 four-node isoparametric linear elements (four temperature degrees of freedom per element). This mesh was found to be suitable after spatial convergence tests. A pavement surface layer built on top of a concrete layer is located at the middle of the domain and surrounded by a homogeneous clay soil. Physical and thermal properties are listed in Table 2. Lower and far-field boundary conditions are set as adiabatic. The overall size of the domain (in particular the position of the vertical and lower horizontal domain boundaries) was considered by way of numerical experiments to ensure that the far-field boundary conditions do not impact on the results. Two theoretical formulations are utilised to describe the domain surface. The pavement surface is described using Equation 2 by adjusting the optical parameters (listed in Table 1) and assuming no evaporation (i.e. the surface is impermeable and rainfall is assumed to run off quickly). The soil surface, based on the results obtained in the previous section, is described using Equations 5 and 6 to take into account the presence of vegetation cover.

In this section of the study, three alternative sources of meteorological data are considered. These are based on: $(a)$ TRL, measured on-site data recorded by Carder et al. (2007); (b) British Atmospheric Data Centre (BADC), a publicly available data source (UK Meteorological Office, 2012); and (c) analytical data, data produced by the analytical Equations 8 and 9 (Cleall et al., 2015). When the analytical approach is used, the relative humidity and wind speed values are assumed constant and equal to $80.6 \%$ and $1.14 \mathrm{~m} / \mathrm{s}$, respectively based on annual averages of the experimental meteorological data provided by Carder et al. (2007). In addition to meteorological data analysis, solar radiation levels reaching the paved surface are modified using Equation 7 to take into account diurnal shading. The pavement is assumed to be shaded between 12.00 and $15.00 \mathrm{~h}$ every day in every yearly cycle. Three levels of shading are compared: $0 \%$ (no shade), $50 \%$ and $100 \%$ (full shade). As previously, a preliminary period of eight yearly cycles was run to achieve an approximation of the non-homogenous temperature field that is employed to define initial conditions for the subsequent simulation. Numerical results from the ninth yearly cycle are then compared with experimental measurements corresponding to $\mathrm{Bh} 2$ (Figure 1).

Figure 10 shows a comparison of the experimental and numerical soil surface temperature every $6 \mathrm{~h}$ at depths of $0 \cdot 01,0 \cdot 875$ and

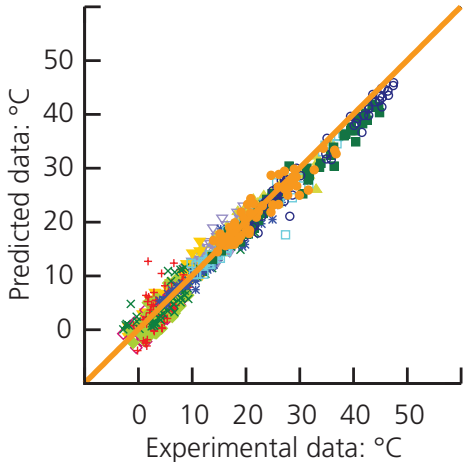

September

October

November

December

January

February

March

April

May

June

- July

- August

Ideal fit

Best fit

(a)

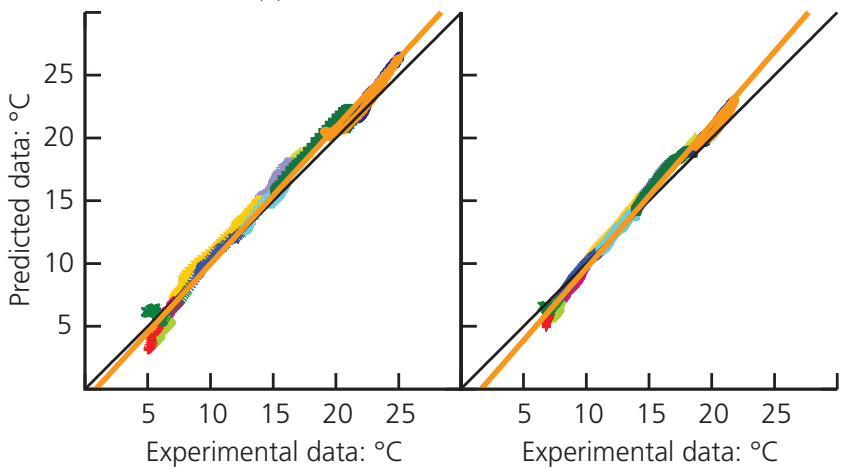

(b)

(c)

Figure 10. Scatter plots of experimental and predicted temperatures at depths of (a) 0.01, (b) 0.875 and (c) $1.375 \mathrm{~m}$ under road (Bh2) using 50\% shading conditions and meteorological data measured on-site by Carder et al. (2007)

$1.375 \mathrm{~m}$ obtained with meteorological data measured on-site (TRL). It can be seen that, in general, the numerical results are in good agreement with the experimental measurements (RMSE values are presented in Table 5). Peak temperatures reach nearly $50^{\circ} \mathrm{C}$ in July and $-4^{\circ} \mathrm{C}$ in winter at $0.01 \mathrm{~m}$ depth. In comparison, the results at $0.025 \mathrm{~m}$ depth in the far-field soil conditions (Figure 4) show maximum and minimum temperatures of 28 and $1^{\circ} \mathrm{C}$. This exemplifies the impact of a higher level of solar absorptivity in the road surface. It can also be seen that the seasonal temperature variation at depths of 0.875 and $1.375 \mathrm{~m}$ is further reduced to between 5 and $25^{\circ} \mathrm{C}$, and 4 and $22^{\circ} \mathrm{C}$, respectively. It is noted that there is a comparatively higher rate of decrease in the maximum temperatures. This seems to indicate that the seasonal effect of solar radiation on temperature tends to be predominantly confined to regions close to the surface.

Figure 11 shows a comparison between experimental and numerical daily averages of soil temperature at depths of 0.01 , 0.875 and $1.375 \mathrm{~m}$ for the period between September 2005 and March 2006. The numerical results were obtained using meteorological data measured on-site (TRL) provided by Carder et al. (2007). Three different levels of shading $(0,50,100 \%)$ were employed in the simulations using Equation 7 between 12.00 and $15.00 \mathrm{~h}$ daily. The results show that, in general, temperatures 


\begin{tabular}{|c|c|c|c|c|c|}
\hline & \multicolumn{3}{|c|}{$\mathrm{TRL}$} & \multirow{2}{*}{$\frac{\text { BADC }}{50 \% \text { shading }}$} & \multirow{2}{*}{$\frac{\text { Analytical equations }}{50 \% \text { shading }}$} \\
\hline & ०\% shading & $50 \%$ shading & $100 \%$ shading & & \\
\hline 0.010 & $4 \cdot 16$ & 3.03 & $4 \cdot 72$ & $2 \cdot 81$ & 4.99 \\
\hline 0.875 & $2 \cdot 45$ & 0.93 & 1.82 & 0.73 & 1.61 \\
\hline $1 \cdot 375$ & $2 \cdot 05$ & 0.87 & 1.77 & 0.71 & $1 \cdot 26$ \\
\hline
\end{tabular}

Table 5. RMSE values for comparisons between experimental and numerical data corresponding to road temperatures (Bh2) at three different depths and shading levels and using alternative meteorological data sources

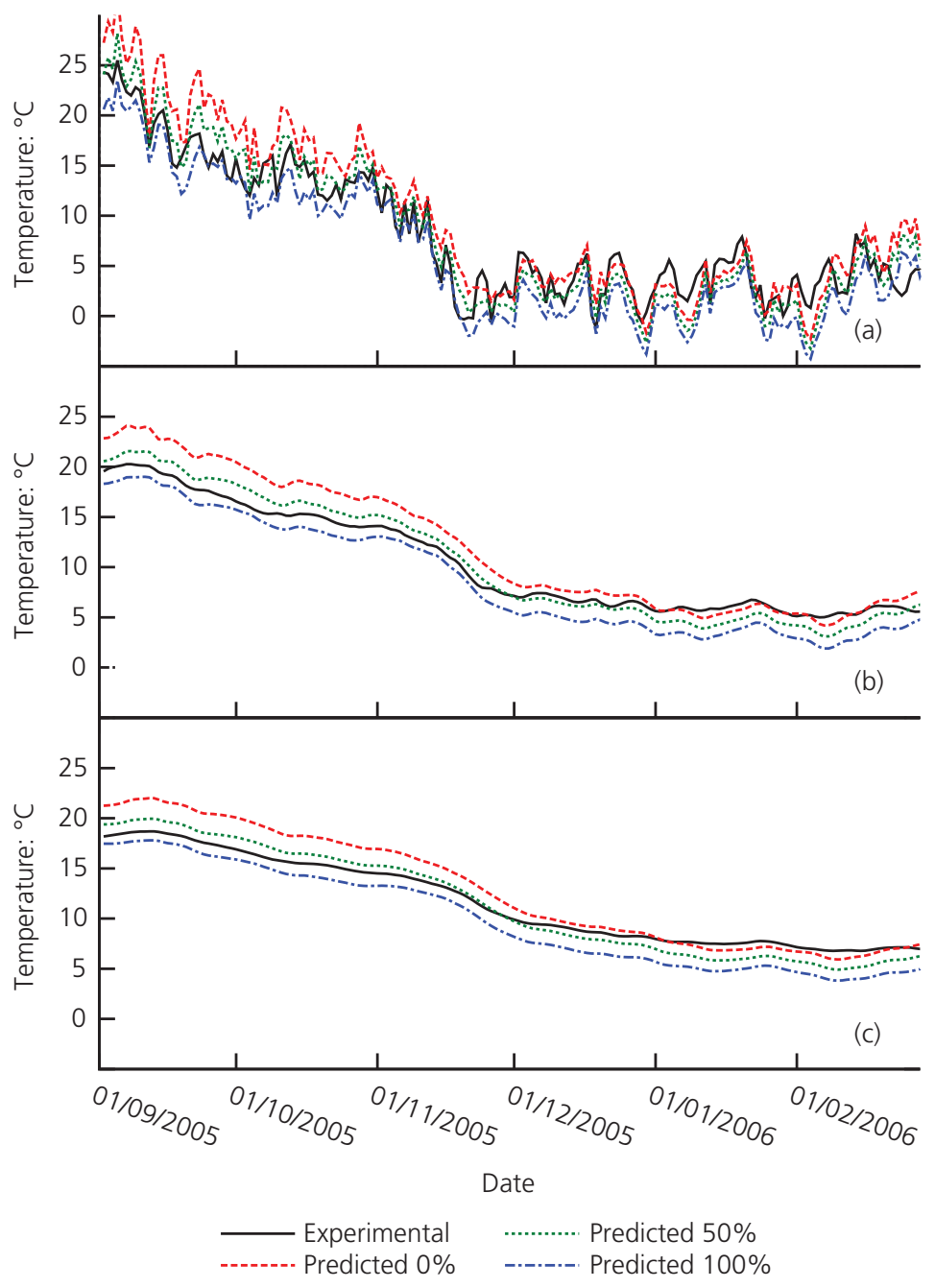

Figure 11. Comparison of experimental and numerical seasonal variations of daily average soil temperatures under road (Bh2) at depths of (a) 0.01 , (b) 0.875 and (c) $1.375 \mathrm{~m}$ for three levels of shading using meteorological data measured on-site by Carder et al. (2007) 
obtained with $0 \%$ shading are constantly higher than those obtained with 50 and $100 \%$ shading, as expected. Differences in soil temperatures of up to 8,6 and $4^{\circ} \mathrm{C}$ between 0 and $100 \%$ shading can be observed at depths of $0.01,0.875$ and $1.375 \mathrm{~m}$, respectively, during September 2005. These differences are reduced during the winter months as the solar radiation contribution to the surface energy budget diminishes. It can also be observed that the seasonal amplitude in the experimental results is lower than that obtained numerically. This is thought to be related to seasonal changes in the level of shading (e.g. seasonal changes in tree leaf area).

Figure 12 compares experimental and numerical hourly soil temperatures at $0 \cdot 1 \mathrm{~m}$ depth for the period 13-16 September 2005. These days were chosen as representative to exemplify the effect of shading on the pavement temperature (this effect can also be observed on many other days). The numerical results were obtained using the three forms of meteorological data (TRL, BADC and analytical). The TRL results were obtained using three levels of shading, while the BADC results and analytical results were obtained for $50 \%$ shading. It can observed that the TRL results obtained with 0 and $100 \%$ shading differ from the experimental data by approximately $5^{\circ} \mathrm{C}$ during daytime. Conversely, results with $50 \%$ shading are closer to the experimental data with differences of the order of $1^{\circ} \mathrm{C}$. However, during night-time, differences of up to $6^{\circ} \mathrm{C}$ are obtained for $100 \%$ shading. This is believed to be related to infrared cooling, which is dependent on the level of sky cloudiness and which, in this study, has been assumed to be constant. Numerical results obtained using BADC data and analytical expressions for $50 \%$ shading are also shown in Figure 12. It can be seen that the BADC results are comparable to those obtained using TRL data, while the analytical expressions, although offering a reasonable trend, tend to underpredict soil surface temperatures at $0.1 \mathrm{~m}$ depth.

Figure 13 compares daily averages of soil temperature obtained from experimental measurements and numerical simulations using the three sets of meteorological data. Results are shown for $50 \%$ shading conditions at depths of $0.01,0.875$ and $1.375 \mathrm{~m}$. The period between September 2005 and March 2006 is considered. As discussed for Figure 12, it can be seen that the TRL and BADC results provide comparable predictions for these three depths with differences of the order of $1{ }^{\circ} \mathrm{C}$. The results based on the analytical expressions provide reasonably good trends, particularly for the 0.875 and $1.375 \mathrm{~m}$ depths but, as would be expected, do not represent the impact of irregular variations in daily weather.

\section{Conclusions}

A numerical heat transfer model has been described that is capable of representing the complex processes that contribute to the surface heat flux budget. The model has been applied to estimate soil temperature variations in the vicinity of a field-scale demonstration project on interseasonal heat storage beneath a paved highway. A series of $1 \mathrm{D}$ and $2 \mathrm{D}$ simulations was undertaken to explore specific characteristics of the facility. In particular, the research focused on assessing the performance of a range of theoretical formulations to represent the complex process that occur at the soil surface. This includes the influence of shading produced by nearby objects and the use of alternative sources of meteorological data. The numerical results have been compared with experimental data provided by Carder et al. (2007).

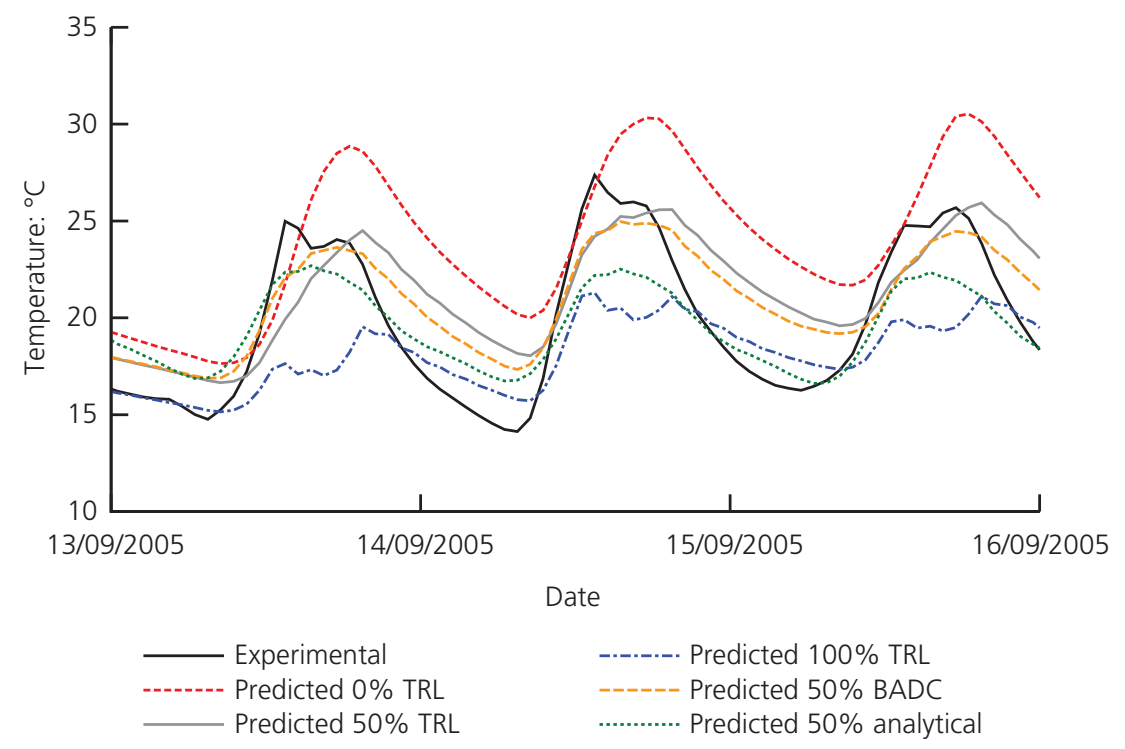

Figure 12. Comparison of experimental and numerical temperatures with time at $0.01 \mathrm{~m}$ depth under the road (Bh2) using 0,50 and $100 \%$ shading conditions 


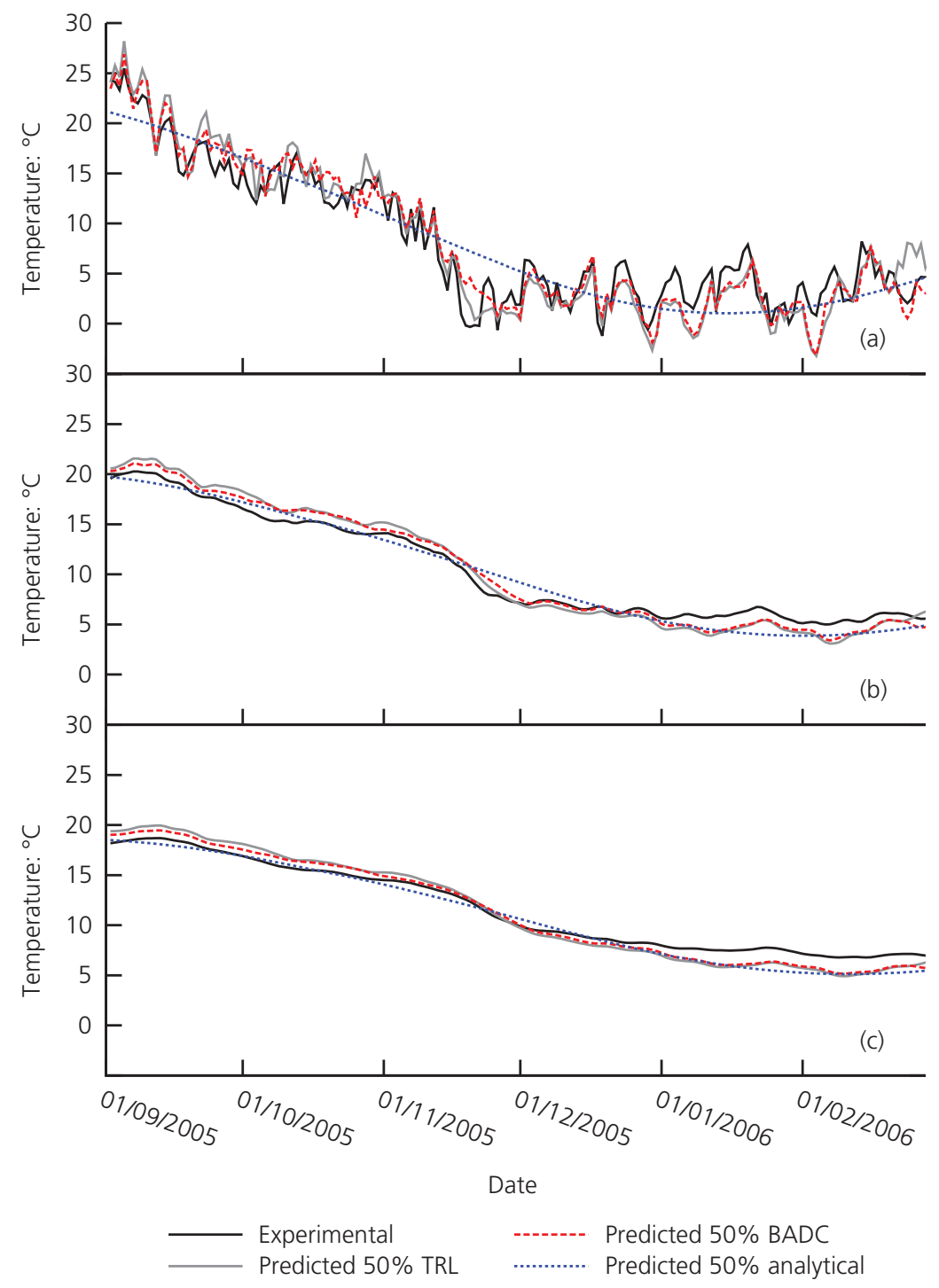

Figure 13. Comparison of experimental and numerical seasonal variations of daily average soil temperatures under road (Bh2) at depths of (a) 0.01 , (b) 0.875 and (c) $1.375 \mathrm{~m}$ under $50 \%$ shading conditions using three sources of meteorological data

It was found that using a theoretical model for bare soil conditions resulted in predictions of the soil surface reaching a higher variation in amplitudes of daily and seasonal temperatures than that observed experimentally. The inclusion of a canopy layer in the theoretical formulation, which allows consideration of the impact of vegetation acting as a buffer between the atmospheric conditions and the soil surface, reduces these variations and results in a much closer correlation with observed behaviour. Similarly, when considering seasonal variations in thermal energy stored in a $12.875 \mathrm{~m}$ soil column, which are of the order of $55 \mathrm{MJ} / \mathrm{m}^{2}$ under UK weather conditions, it was found that employing a theoretical model that considers canopy cover correlated well with observed values; however, when only bare soil was considered, differences of up to $15 \mathrm{MJ} / \mathrm{m}^{2}$ were found. It is suggested that representation of the effects of possible seasonal changes in the canopy layer and the inclusion of soil moisture changes in the model description could potentially improve the correlations further.

A simplified study of different levels of shading over a road surface for a selected period of time showed that the impact on surface temperature can be of the order of $8^{\circ} \mathrm{C}$ when comparing fully shaded with unshaded conditions. It is suggested that this effect varies seasonally as solar radiation decreases from summer to winter. Further study of the influence of seasonal variations in shading produced by natural objects (e.g. tree canopies) and the effect of clouds in nocturnal cooling appears necessary to provide a more comprehensive model. 
Alternative methods of defining meteorological conditions at the soil surface have also been explored. The results showed that weather information obtained from publicly available sources offers results comparable to those obtained from measurements carried on-site (with temperature differences of the order of $1^{\circ} \mathrm{C}$ ). In the absence of adequate experimental weather measurements, it has been shown that analytical expressions for air temperature and solar radiation, readily available in the literature (Cleall et al., 2015), can offer a suitable representation of the seasonal variation in soil surface temperatures. The results from this approach were found to be comparable to those obtained using on-site weather measurements, particularly in slightly deeper regions.

Overall, it can be concluded that correct assessment of the nature of heat transfer processes occurring on the surface of the soil is of critical importance for the estimation of the amount of heat energy stored in near-surface soil layers. Ultimately, this information is important for the effective design and assessment of soil-based heat storage facilities.

\section{Acknowledgements}

The authors gratefully acknowledge the support given to the first author, whose PhD studies were funded by the Mexican National Council of Science and Technology and the Mexican Secretariat of Public Education. Also, the authors are grateful to TRL/HA for release of the source data published in Carder et al. (2007).

\section{REFERENCES}

Best MJ (1998) A model to predict surface temperatures.

Boundary-Layer Meteorology 88: 279-306, http://dx.doi.org/ 10.1023/A:1001151927113.

Bobes-Jesus V, Pascual-Muñoz P, Castro-Fresno D and RodriguezHernandez J (2013) Asphalt solar collectors: a literature review. Applied Energy 102: 962-970, http://dx.doi.org/10. 1016/j.apenergy.2012.08.050.

Carder DR, Barker KJ, Hewitt MG, Ritter D and Kiff A (2007) Performance of an Interseasonal Heat Transfer Facility for Collection, Storage and Re-use of Solar Heat from the Road Surface. Transport Research Laboratory, Wokingham, UK, No. PPR302.

Cleall PJ, Muñoz-Criollo JJ and Rees SW (2015) Analytical solutions for ground temperature profiles and stored energy using meteorological data. Transport in Porous Media 106: 181-199, http://dx.doi.org/10.1007/s11242-014-0395-3.

Deardorff J (1978) Efficient prediction of ground surfacetemperature and moisture, with inclusion of a layer of vegetation. Journal of Geophysical Research: Oceans 83: 1889-1903, http://dx.doi.org/10.1029/JC083iC04p01889.

Edinger JE and Brady DK (1974) Heat Exchange and Transport in the Environment. John Hopkins University, Baltimore, MD, USA.

Florides G and Kalogirou S (2007) Ground heat exchangers - a review of systems, models and applications. Renewable Energy 32: 2461-2478, http://dx.doi.org/10.1016/j.renene.2006.12.014.

Garratt JR (1994) The Atmospheric Boundary Layer. Cambridge University Press, Cambridge, UK.
Google Maps (2012) Toddington Service Area, Toddington. Google, Mountain View, CA, USA. See http://maps.google.co. uk/ (accessed 17/02/2012).

Herb WR, Janke B, Mohseni O and Stefan HG (2008) Ground surface temperature simulation for different land covers. Journal of Hydrology 356: 327-343, http://dx.doi.org/10.1016/ j.jhydrol.2008.04.020.

Jansson C, Almkvist E and Jansson P (2006) Heat balance of an asphalt surface: observations and physically-based simulations. Meteorological Applications 13: 203-212, http://dx.doi.org/10. 1017/S1350482706002179.

Muñoz-Criollo JJ (2014) An Investigation of Inter-seasonal Nearsurface Ground Heat Transfer and Storage. PhD thesis, Cardiff University, Cardiff, UK.

Muñoz-Criollo JJ, Cleall PJ and Rees SW (2016) Factors influencing collection performance of near surface interseasonal ground energy collection and storage systems. Geomechanics for Energy and the Environment 6: 45-57, http://dx.doi.org/10.1016/j.gete.2016.04.001.

North GR and Erukhimova TL (2009) Atmospheric Thermodynamics: Elementary Physics and Chemistry. Cambridge University Press, Cambridge, UK.

Pascual-Muñoz P, Castro-Fresno D, Carpio J and Zamora-Barraza D (2014) Influence of early colour degradation of asphalt pavements on their thermal behaviour. Construction and Building Materials 65: 432-439, http://dx.doi.org/10.1016/j. conbuildmat.2014.05.028.

Pinel P, Cruickshank CA, Beausoleil-Morrison I and Wills A (2011) A review of available methods for seasonal storage of solar thermal energy in residential applications. Renewable \& Sustainable Energy Reviews 15: 3341-3359, http://dx.doi.org/ 10.1016/j.rser.2011.04.013.

Rees SW, Adjali MH, Zhou Z, Davies M and Thomas HR (2000) Ground heat transfer effects on the thermal performance of earthcontact structures. Renewable \& Sustainable Energy Reviews 4: 213-265, http://dx.doi.org/10.1016/S1364-0321(99)00018-0.

UK Meteorological Office (2012) Met Office Integrated Data Archive System (MIDAS) Land and Marine Surface Stations Data (1853-Current). British Atmospheric Data Centre, National Centre for Atmospheric Science, Oxford, UK. See http://badc.nerc.ac.uk/view/badc.nerc.ac.uk_ATOM dataent_ukmo-midas (accessed/03/04/2014).

Zoras S (2009) A review of building earth-contact heat transfer. Advances in Building Energy Research 3: 289-314, http://dx. doi.org/doi:10.3763/aber.2009.0312.

\section{How can you contribute?}

To discuss this paper, please submit up to 500 words to the editor at journals@ice.org.uk. Your contribution will be forwarded to the author(s) for a reply and, if considered appropriate by the editorial board, it will be published as a discussion in a future issue of the journal. 